\title{
Changes of the adjacent discs and vertebrae in patients with osteoporotic vertebral compression fractures treated with or without bone cement augmentation
}

\begin{abstract}
Background Context: Although vertebral augmentation with bone cement has been commonly used to treat symptomatic osteoporotic vertebral compression fractures, relatively little is known about the impact of augmentation on the adjacent spinal components.
\end{abstract}

Purpose: To determine the imaging effects of vertebral augmentation on the adjacent discs, the augmented vertebra, and the involved spinal segment.

Study Design: Retrospective radiographic study.

Patient Sample: Patients with acute osteoporotic vertebral compression fractures who underwent vertebral augmentation or nonoperative treatments.

Outcome Measures: On baseline and follow-up mid-sagittal T2W magnetic resonance images, quantitative measurements of disc degeneration, including disc height, bulging, and signal, vertebral height, wedge angle, and segmental kyphotic angle were acquired.

Methods: Lumbar spine magnetic resonance images of patients with acute osteoporotic vertebral compression fractures at a local hospital in Eastern China between 2010 and 2017 were reviewed. Student's t-tests and $\chi^{2}$ tests were used to examine the differences of baseline and changes over time between vertebrae underwent vertebral augmentation and those did not. Paired t-tests were used to examine the differences between baseline 
and follow-up to study the changes of adjacent disc degeneration, creep deformity of the vertebra and progression of segmental kyphosis.

Results: There were 112 acute vertebral compression fractures (72 treated with kyphoplasty and 40 with nonoperative treatments) in 101 subjects. At final follow-up (mean 21.5 months), the cranial disc of the augmented vertebra decreased in height $(\mathrm{p}<0.001)$, and both cranial and caudal discs decreased in signal intensity $(\mathrm{p} \leq 0.02)$. The discs in the nonoperative group did not undergo such degenerative changes. For the fractured vertebra, vertebral height significantly decreased ( $p<0.01$ for both) and vertebral wedge angle significantly increased $(\mathrm{p} \leq 0.01$ for both), regardless of augmentation treatment or not. Segmental kyphotic angle significantly increased in vertebral fractures that underwent vertebral augmentation $(\mathrm{p}<0.001)$, but not in those underwent nonoperative treatments.

Conclusions: Patients that underwent vertebral augmentation had more advanced disc degeneration at adjacent disc levels as compared to those without augmentation. The fractured vertebral body height decreased and the wedge angle increased, regardless of vertebral augmentation treatment or not. Vertebral augmentation may be associated with increased creep deformity of the adjacent vertebra and the progression of segmental kyphosis.

Key words: vertebral compression fractures, vertebral augmentation, disc degeneration, creep deformity, kyphosis, magnetic resonance imaging

\section{Level of evidence: III.}




\section{Introduction}

As a common complication of osteoporosis, vertebral compression fractures often result in significant back pain[1]. Although most symptomatic vertebral compression fractures can be treated nonoperatively, some patients fail to respond to nonoperative treatments and suffer from persistent back pain or even disability[2]. Percutaneous vertebral augmentation with bone cement is a commonly used procedure to treat this subgroup of patients with symptomatic vertebral compression fractures[3].

Although vertebral augmentation was generally thought to be able to achieve rapid pain relief and quick function recovery[4-6], such effects were not observed in two high quality randomized sham-controlled trials[7,8]. On the other hand, vertebral augmentation with bone cement has been thought to potentially predispose the adjacent vertebra to fractures[9]. Biomechanical studies also demonstrated that bone cement can enhance mechanical stiffness of the augmented vertebra, and consequently alter the transfer of loading to the adjacent discs and vertebrae[10]. Vertebral augmentation, therefore, may have profound mechanical impacts on the adjacent spinal components.

Relatively little is known about the impacts of bone cement augmentation on the adjacent intervertebral disc. There are theoretical concerns that the filled bone cement, especially that in a large volume, can impair nutrient supply to the adjacent disc and lead to disc degeneration[11]. In a rabbit model of vertebral augmentation, increased nucleus cell apoptosis and annulus disruption were observed in the disc adjacent to the augmented vertebra[12], evidence that vertebral augmentation may accelerate adjacent 
disc degeneration. Yet, clinical knowledge of the impacts of vertebral augmentation on the adjacent disc is sparse.

Biomechanical studies revealed that the fractured vertebra may continue to deform over time even under physiological load[13,14]. Such a process of gradual deformation of the vertebra was specifically called "creep," and was thought to associate with progressive spinal deformity such as kyphosis[14]. Although biomechanical studies reported that bone cement injection can reduce subsequent creep deformation of the fractured vertebra[15], a gradual decrease of vertebral height was observed in approximately half of the clinical cases underwent vertebroplasty[16]. The relationship between vertebral augmentation and vertebral creep thus needs further investigations.

Using a sample of routine magnetic resonance (MR) images from a local hospital, the current study aimed to determine the effects of bone cement vertebral augmentation on the adjacent discs, the augmented vertebra, and the involved spinal segment. 


\section{Methods}

Study subjects

Data were collected at a local hospital in Eastern China. At this hospital, baseline MR imaging was performed at the first visiting for patients with acute osteoporotic vertebral fractures $(\leq 4$ weeks), and the patients were first treated with various nonoperative therapies. For those older than 55 years and whose back pain lasted for 3 weeks or more were indicated for unilateral percutaneous kyphoplasty under local anesthesia. After routine vertebra biopsy, the surgery was performed by a single spine team and typically 2-4 ml polymethylmethacrylate (PMMA) was injected.

By searching the picture archiving and communication systems (PACS), all patients with a diagnosis of thoracic or lumbar vertebral compression fractures between Jan $1^{\text {st }}$ of 2010 and Dec $31^{\text {st }}$ of 2017 were screened to recruit study samples. Ethical permission was obtained at the author's institution. Informed consent was waived by the ethical review boards as this is a retrospective radiological study.

Inclusion criteria were: 1) older than 55 years; 2) a clear radiological diagnosis of acute vertebral compression fractures at T11-L5 spinal level with baseline MRIs, treated with either kyphoplasty vertebral augmentation or nonoperative treatments; 3) with followup MR imaging performed at least 3 months after the baseline imaging; 4) AO classification type A1 compression vertebral fractures[17]; 5) non-pathologic fractures, as confirmed by biopsy; 6) without a history of lumbar spine surgery.

Exclusion criteria were: 1) younger than 55 years; 2) without follow-up MR images or 
follow-up MR imaging conducted within 3 months; 3) AO classification type A2-4, type $\mathrm{B}$ or $\mathrm{C}$ vertebral fractures, which were with obvious disruptions of the disc or posterior elements[17]; 4) specific spine diseases such as malignancy and infections; 5) history of lumbar spine surgery.

On the basis of percutaneous kyphoplasty vertebral augmentation, subjects were divided into vertebral augmentation group and no vertebral augmentation group. Baseline and follow-up MR images were downloaded in DICOM format for analysis. The patients' information was anonymized and de-identified prior to any data analyses.

\section{MR protocol}

MR imaging was performed using a 1.5 Tesla scanner (Achieva, Philips Medical Systems Corp, Netherland). Sagittal T1-weighted (T1W) images were acquired using fast spin-echo (TSE) sequence with repetition time (TR) of $400 \mathrm{~ms}$ and echo time (TE) of $7.8 \mathrm{~ms}$. The sagittal T2-weighted (T2W) TSE was with a TR of $3500 \mathrm{~ms}$ and a TE of 120 ms. Fat suppression images were acquired using spectral attenuated inversion recovery (SPAIR) sequence (TR $3500 \mathrm{~ms}$, TE $60 \mathrm{~ms}$ ). Section thickness was $4 \mathrm{~mm}$, and intersection gap was $3.6 \mathrm{~mm}$. The matrix size was $336 \times 228$, and field of view was $150 \times 150 \mathrm{~mm}$.

\section{Evaluation of vertebral compression fractures}

A senior radiologist (18-year practice experience) reviewed all the baseline MR images to evaluate the presence or absence of acute vertebral compression fractures. Using image program Mimics (Version 20.0, Materialise Corp, Belgium), acute vertebral 
compression fractures were defined as vertebral collapse or the presence of fracture line within the vertebral body, with significant vertebral marrow edema (increased signal on T2W or SPAIR sequences)[18] (Figure 1).

\section{Measurements of disc degeneration}

The discs immediately adjacent to the fractured vertebra were defined as cranial or caudal adjacent discs, respectively. In addition, the disc proximally neighboring to the fractured spinal motion segment was also measured and taken as an internal control (Figure 2A).

Using Mimics, quantitative measurements of disc degeneration, including disc height, disc bulging, and cerebrospinal fluid (CSF) adjusted disc signal, were acquired on the mid-sagittal T2W MR images[19]. Disc height was defined as the mean of anterior, middle and posterior heights of the non-convex portion of the disc (Figure 2B). Disc bulging, including anterior and posterior bulging, was measured as the area of the disc portion that exceeds the anterior or posterior edges of adjacent vertebral bodies (Figure 2C). Disc signal measurements were sampled in the anterior, middle and posterior regions of the nucleus pulposus, which were further averaged and adjusted using adjacent CSF signal intensity[20] (Figure 2D).

\section{Vertebral creep deformity and kyphotic angles}

Vertebral heights, defined as the mean of anterior, middle and posterior heights of the vertebral body, were acquired for the fractured vertebra and two adjacent vertebrae on the mid-sagittal T2W MR images (Figure 2E). Height of the fractured vertebra was 
further adjusted using the average heights of two adjacent vertebrae. Creep deformity was then examined by comparing the vertebral heights measured at baseline and followup.

On the mid-sagittal MR image, vertebral wedge angle was measured for the fractured vertebra (Figure 2F). Segmental kyphotic angle was measured for the spinal motion segment which consists of the fractured vertebra and two adjacent vertebrae (Figure 2G).

\section{Reliability study}

MR images of 20 subjects were randomly selected and repeatedly evaluated by two orthopedic residents 2 weeks apart to examine intra- and inter-rater agreements for various measurements.

\section{Statistical analysis}

Statistical analyses were performed using Stata (version 13.0, Stata Corp LP, TX, USA). Data were presented as mean \pm standard deviation (SD), and the significance level was set at $\mathrm{p}<0.05$. Intra-class correlation coefficient (ICC) was used to examine measurement reliability. Student's t-tests and $\chi^{2}$ tests were used to examine the differences of baseline and changes over time between vertebrae underwent vertebral augmentation and those did not. Paired t-tests were used to examine the differences between baseline and follow-up to determine the effects of vertebral augmentation on the adjacent discs, the augmented vertebra and the involved spinal segment. 


\section{Results}

In the defined period, 101 subjects ( 31 men and 70 women, aged $71.6 \pm 8.5$ years, range 55-90 years) who met the inclusion criteria were included in the current study. Among them, 9 subjects had 2 discrete vertebral fractures, and 1 subject had 3 discrete vertebral fractures. As a result, there were 112 acute vertebral compression fractures, among which $72(62.0 \%)$ were treated with unilateral percutaneous kyphoplasty and the remaining $40(38.0 \%)$ were treated nonoperatively. There was no statistical difference in age, gender ratio, body mass index, and spinal level between vertebral augmentation and no vertebral augmentation groups. The follow-up time was $21.5 \pm 15.3$ months (range 3 to 65 months). On average, the patients without vertebral augmentation treatment were followed up 6.4 months longer than those underwent vertebral augmentation (Table 1).

\section{Measurement reliability}

Based on ICCs, the intra- and inter-rater agreements for various measurements were good or excellent (Table 2).

\section{Adjacent disc degeneration}

At baseline, there was no statistical difference in disc height and signal between vertebral augmentation and no vertebral augmentation groups $(\mathrm{p}>0.05)$. While the discs cranial to the bone cement augmented vertebrae significantly decreased in height at follow-up $(\mathrm{p}<0.001)$, those adjacent to the fractured vertebra without augmentation treatment did not $(\mathrm{p}=0.10)$. The disc caudally adjacent to the augmented vertebra 
decreased in height but did not reach statistical significance $(p=0.07)$.

While both the cranial and caudal discs adjacent to the augmented vertebra decreased in signal at follow-up $(\mathrm{p}<0.05$ for both), those adjacent to the fractured vertebra without augmentation treatment did not have significant signal loss. No significant change of adjacent disc bulging was observed in both groups ( $\mathrm{p}>0.05$ for all).

The internal control discs in both vertebral augmentation and no vertebral augmentation groups slightly decreased in height at follow-up ( $p=0.004$ and 0.03 , respectively), but did not have statistically significant changes in signal intensity and bulging (Table 3).

Vertebral creep deformity and segmental kyphosis

At baseline, the adjusted height of the fractured vertebra in vertebral augmentation group was greater than that in no vertebral augmentation group $(\mathrm{p}<0.05)$. At follow-up, for the fractured vertebra, adjusted vertebral height significantly decreased $(p \leq 0.01$ for both) and vertebral wedge angle significantly increased ( $\mathrm{p} \leq 0.01$ for both), regardless of vertebral augmentation treatments or not. Moreover, the changes in vertebral height $(p=0.15)$ and vertebral wedge angle $(p=0.46)$ were not statistically different between augmentation and no augmentation groups. The vertebra caudal to the augmented vertebra significantly decreased in height $(p=0.003)$. Segmental kyphotic angle significantly increased in subjects who had vertebral augmentation $(\mathrm{p}<0.001)$, but not in those without vertebral augmentation treatments (Table 4). 


\section{Discussion}

Using quantitative measures, the current study revealed that vertebral augmentation with bone cement had profound impacts on the involved spinal motion segment and its components. Vertebral augmentation led to signal loss and height decrease in the adjacent discs, suggesting that vertebral augmentation with bone cement can accelerate adjacent disc degeneration. Contrast to previous views, the current clinical data suggested that the fractured vertebral body height decreased and the wedge angle increased, regardless of vertebral augmentation treatments or not. Furthermore, vertebral augmentation may associate with increased creep deformity of the adjacent vertebra and increased segmental kyphosis.

Although vertebral augmentation procedure is commonly used in clinical practice for treating osteoporotic vertebral compression fractures, impacts of vertebral augmentation on the adjacent discs remain unclear. Although it has been noticed that vertebral augmentation may promote adjacent disc degeneration[21], such finding was not confirmed in another study[22]. Other than small sample size and short follow-up time, evaluation of disc degeneration with Pfirrmann scale may be a reason, as this qualitative scale is insensitive to detect the changes of disc degeneration over time[23]. Echoing a recent study using T2 mapping techniques to detect a significant loss of disc signal following kyphoplasty[24], the current work used routine T2W sequence and techniques of quantitative image analysis and observed both the cranial and caudal discs adjacent to the augmented vertebra underwent signal loss at follow-up. Moreover, the cranial adjacent disc decreased in height after vertebral augmentation, suggesting that 
profound structural changes may have occurred in the adjacent discs.

Impairment of nutrient supply to the disc and altered local biomechanics, both resulted from vertebral augmentation, may contribute to the accelerated adjacent disc degeneration. As diffusion through the endplate is the main path of nutrient supply to the disc, the blockage of this pathway can lead to nutrient deprivation in the nucleus and eventually disc degeneration[25,26]. Filling bone cement in the trabeculae beneath the endplate can damage capillaries there (a process also called de-vascularization) and occupy the space for capillary reconstruction, resulting in impaired local vascularization[27]. Such vascular impairment was evidenced in our previous animal experiments that followed bone cement augmentation approximately half of marrow contact channels[28] in the endplate were without resident erythrocytes[12]. With decreased nutrient supply, increased proteoglycan loss and cell apoptosis occurred in the nucleus, which ultimately led to disc degeneration[11,12,29]. On the other hand, bone cement filling increased elastic modulus of the fractured vertebra and thus, can reflect greater stress and strain to the adjacent discs and vertebrae[30,31]. Such altered biomechanical environment in the involved spinal segment, therefore, may promote adjacent disc degeneration[32,10].

This clinical study investigated the associations of vertebral augmentation with creep deformity of the fractured and adjacent vertebrae. Previous biomechanical studies using cadaveric spines reported that vertebral fractures can increase creep deformation of the fractured vertebra (particularly in the anterior portion of the vertebra) and vertebral augmentation can reduce such creep deformation[33]. In the current study, however, 
decreased vertebral height and increased wedge angle were observed in the fractured vertebra, regardless of with or without bone cement augmentation, suggesting that vertebral augmentation may not be able to stop creep deformation. Furthermore, a decrease of vertebral height was observed for the vertebra caudally adjacent to the augmented vertebra. Reasons underlying the increased creep deformation of the adjacent vertebra may be undetected microdamage there[34], increased loading due to vertebral augmentation[30], or both.

Many studies reported that vertebral augmentation can reduce segmental kyphosis angle[35,36]. In the present study, however, segmental kyphosis progressed in those who underwent vertebral augmentation but not in those without augmentation treatments, questioning such point of view. It is possible that segmental kyphosis angle was temporarily correct at vertebral augmentation procedure but the correction of kyphosis angle cannot be maintained over time. The increase of wedge angle at the fractured vertebra and the decreases of vertebral and disc heights at the adjacent levels may all contribute to the progression of segmental kyphosis. Yet, the clinical significance of such kyphosis progression remains unclear.

This retrospective radiological study investigated a relatively large sample of patients with acute vertebral compression fractures. Despite data were collected at a local hospital and all subjects who met the inclusion criteria within a defined period were included, there may be sampling bias as only those with severe pain which did not respond to nonoperative treatments within 3 weeks were indicated for percutaneous kyphoplasty and reasons for follow-up MR imaging remain unknown. Some factors 
which may influence study observations, including the volume of injected bone cement, the degree of osteoporosis, and the post-operative status of a vertebra immediately after augmentation procedure, were not studied due to the unavailability of related data. Yet, the focuses of the current study are overtime morphological changes in the adjacent disc and vertebra followed vertebral augmentation. While vertebral compression fractures can occur in any thoracic level, we only studied those involved T11-L5 vertebrae as discs here are relatively more important in terms of disc degeneration. Although CT scans and standing radiographs are better than MR imaging in the evaluations of vertebral creep and segmental kyphosis, we used only MR images. Various disc degeneration phenotypes were quantitatively measured, which were more objective and sensitive than ordinal scales, to detect the changes of disc degeneration over time. Moreover, the average follow-up time was merely 2 years, which may not be long enough to fully illustrate the consequences of vertebral augmentation in neighboring spinal components. Yet, the effects of vertebral augmentation on adjacent disc degeneration and segmental kyphosis were apparent, even though these subjects were followed-up 6.4 months shorter than those who did not undergo vertebral augmentation. As such, greater changes in the adjacent discs and segmental kyphosis following vertebral augmentation are expected in long-term follow-up. As we did not investigate clinical symptoms, which is an obvious flaw of the current study, clinical relevance of study findings remains unknown. 


\section{Conclusions}

Patients that underwent vertebral augmentation had more advanced disc degeneration at adjacent disc levels, as compared to those without augmentation. The fractured vertebral body height decreased and the wedge angle increased, regardless of vertebral augmentation treatments or not. Vertebral augmentation may associate with increased creep deformity of the adjacent vertebra and the progression of segmental kyphosis. Prospective longitudinal study is needed to fully understand the impacts of vertebral augmentation on the adjacent spinal components and involved spinal segment. 


\section{References}

[1] Bliuc D, Nguyen ND, Milch VE, Nguyen TV, Eisman JA, Center JR (2009) Mortality risk associated with low-trauma osteoporotic fracture and subsequent fracture in men and women. JAMA 301 (5):513-521. doi:10.1001/jama.2009.50

[2] Kanis JA, Johnell O (1999) The burden of osteoporosis. J Endocrinol Invest 22 (8):583-588

[3] McGraw JK, Cardella J, Barr JD, Mathis JM, Sanchez O, Schwartzberg MS et al. (2003) Society of Interventional Radiology quality improvement guidelines for percutaneous vertebroplasty. J Vasc Interv Radiol 14 (7):827-831

[4] Alvarez L, Alcaraz M, Perez-Higueras A, Granizo JJ, de Miguel I, Rossi RE et al. (2006) Percutaneous vertebroplasty: functional improvement in patients with osteoporotic compression fractures. Spine (Phila Pa 1976) 31 (10):1113-1118. doi:10.1097/01.brs.0000216487.97965.38

[5] Ploeg WT, Veldhuizen AG, The B, Sietsma MS (2006) Percutaneous vertebroplasty as a treatment for osteoporotic vertebral compression fractures: a systematic review. Eur Spine J 15 (12):1749-1758. doi:10.1007/s00586-006-0159-z

[6] Wardlaw D, Cummings SR, Van Meirhaeghe J, Bastian L, Tillman JB, Ranstam J et al. (2009) Efficacy and safety of balloon kyphoplasty compared with non-surgical care for vertebral compression fracture (FREE): a randomised controlled trial. Lancet 373 (9668):1016-1024. doi:10.1016/S0140-6736(09)60010-6

[7] Kallmes DF, Comstock BA, Heagerty PJ, Turner JA, Wilson DJ, Diamond TH et al. (2009) A randomized trial of vertebroplasty for osteoporotic spinal fractures. N Engl J Med 361 (6):569-579. doi:10.1056/NEJMoa0900563

[8] Buchbinder R, Osborne RH, Ebeling PR, Wark JD, Mitchell P, Wriedt C et al. (2009) A randomized trial of vertebroplasty for painful osteoporotic vertebral fractures. $\mathrm{N}$ Engl J Med 361 (6):557-568. doi:10.1056/NEJMoa0900429

[9] Trout AT, Kallmes DF, Kaufmann TJ (2006) New fractures after vertebroplasty: adjacent fractures occur significantly sooner. AJNR Am J Neuroradiol 27 (1):217223

[10] Baroud G, Nemes J, Heini P, Steffen T (2003) Load shift of the intervertebral disc after a vertebroplasty: a finite-element study. Eur Spine J 12 (4):421-426. doi:10.1007/s00586-002-0512-9

[11] Kang R, Li H, Ringgaard S, Rickers K, Sun H, Chen M et al. (2014) Interference in the endplate nutritional pathway causes intervertebral disc degeneration in an immature porcine model. Int Orthop 38 (5):1011-1017. doi:10.1007/s00264-0142319-9

[12] Feng Z, Chen L, Hu X, Yang G, Wang Y, Chen Z (2018) Vertebral Augmentation 
can Induce Early Signs of Degeneration in the Adjacent Intervertebral Disc: Evidence from a Rabbit Model. Spine (Phila Pa 1976). doi:10.1097/BRS.0000000000002666

[13] Pollintine P, Luo J, Offa-Jones B, Dolan P, Adams MA (2009) Bone creep can cause progressive vertebral deformity. Bone 45 (3):466-472. doi:10.1016/j.bone.2009.05.015

[14] Adams MA, Dolan P (2011) Biomechanics of vertebral compression fractures and clinical application. Arch Orthop Trauma Surg 131 (12):1703-1710. doi:10.1007/s00402-011-1355-9

[15] Luo J, Pollintine P, Annesley-Williams DJ, Dolan P, Adams MA (2016) Vertebroplasty reduces progressive creep' deformity of fractured vertebrae. J Biomech 49 (6):869-874. doi:10.1016/j.jbiomech.2015.09.006

[16] Oh HS, Kim TW, Kim HG, Park KH (2016) Gradual Height Decrease of Augmented Vertebrae after Vertebroplasty at the Thoracolumbar Junction. Korean J Neurotrauma 12 (1):18-21. doi:10.13004/kjnt.2016.12.1.18

[17] Aebi M (2010) Classification of thoracolumbar fractures and dislocations. Eur Spine J 19 Suppl 1:S2-7. doi:10.1007/s00586-009-1114-6

[18] Buchbinder R, Osborne RH, Ebeling PR, Wark JD, Mitchell P, Wriedt CJ et al. (2008) Efficacy and safety of vertebroplasty for treatment of painful osteoporotic vertebral fractures: a randomised controlled trial [ACTRN012605000079640]. BMC Musculoskelet Disord 9:156. doi:10.1186/1471-2474-9-156

[19] Feng Z, Liu Y, Wei W, Hu S, Wang Y (2016) Type II Modic Changes May not Always Represent Fat Degeneration: A Study Using MR Fat Suppression Sequence. Spine (Phila Pa 1976) 41 (16):E987-994. doi:10.1097/BRS.0000000000001526

[20] Videman T, Gibbons LE, Battie MC (2008) Age- and pathology-specific measures of disc degeneration. Spine (Phila $\mathrm{Pa}$ 1976) 33 (25):2781-2788. doi:10.1097/BRS.0b013e31817e1d11

[21] Qian J, Yang H, Jing J, Zhao H, Ni L, Tian D et al. (2012) The early stage adjacent disc degeneration after percutaneous vertebroplasty and kyphoplasty in the treatment of osteoporotic VCFs. PLoS One 7 (10):e46323. doi:10.1371/journal.pone.0046323

[22] Konig MA, Panzer S, Schulz J, Bierschneider M, Boszczyk BM (2015) Magnetic resonance imaging changes of intervertebral discs after kyphoplasty. Eur Spine J 24 (4):724-733. doi:10.1007/s00586-014-3244-8

[23] Griffith JF, Wang YX, Antonio GE, Choi KC, Yu A, Ahuja AT et al. (2007) Modified Pfirrmann grading system for lumbar intervertebral disc degeneration. Spine (Phila Pa 1976) 32 (24):E708-712. doi:10.1097/BRS.0b013e31815a59a0

[24] Pachowsky ML, Kleyer A, Wagner L, Langenbach A, Simon D, Janka R et al. 
(2018) Quantitative T2 Mapping Shows Increased Degeneration in Adjacent Intervertebral Discs Following Kyphoplasty. Cartilage:1947603518758434. doi:10.1177/1947603518758434

[25] van der Werf M, Lezuo P, Maissen O, van Donkelaar CC, Ito K (2007) Inhibition of vertebral endplate perfusion results in decreased intervertebral disc intranuclear diffusive transport. J Anat 211 (6):769-774. doi:10.1111/j.1469-7580.2007.00816.x

[26] Nachemson A, Lewin T, Maroudas A, Freeman MAR (1970) In-Vitro Diffusion Of Dye Through End-Plates And Annulus Fibrosus Ofhuman Lumbar Inter-Vertebral Discs. Acta Orthop Scand 41 (6):589-+. doi:Doi 10.3109/17453677008991550

[27] Hao J, Hu Z (2012) Percutaneous cement vertebroplasty in the treatment of symptomatic vertebral hemangiomas. Pain Physician 15 (1):43-49

[28] Benneker LM, Heini PF, Alini M, Anderson SE, Ito K (2005) 2004 Young Investigator Award Winner: vertebral endplate marrow contact channel occlusions and intervertebral disc degeneration. Spine (Phila Pa 1976) 30 (2):167-173

[29] Ding F, Shao ZW, Xiong LM (2013) Cell death in intervertebral disc degeneration. Apoptosis 18 (7):777-785. doi:10.1007/s10495-013-0839-1

[30] Polikeit A, Nolte LP, Ferguson SJ (2003) The effect of cement augmentation on the load transfer in an osteoporotic functional spinal unit: finite-element analysis. $\begin{array}{llllll}\text { Spine } & \text { (Phila } & \mathrm{Pa} & 1976) & 28 & (10): 991-996 .\end{array}$ doi:10.1097/01.BRS.0000061987.71624.17

[31] Keller TS, Kosmopoulos V, Lieberman IH (2005) Vertebroplasty and kyphoplasty affect vertebral motion segment stiffness and stress distributions: a microstructural finite-element study. Spine (Phila Pa 1976) 30 (11):1258-1265

[32] Tzermiadianos MN, Renner SM, Phillips FM, Hadjipavlou AG, Zindrick MR, Havey RM et al. (2008) Altered disc pressure profile after an osteoporotic vertebral fracture is a risk factor for adjacent vertebral body fracture. European Spine Journal 17 (11):1522-1530. doi:10.1007/s00586-008-0775-x

[33] Luo J, Annesley-Williams DJ, Adams MA, Dolan P (2017) How are adjacent spinal levels affected by vertebral fracture and by vertebroplasty? A biomechanical study $\begin{array}{llllll} & \text { on } & \text { cadaveric } & \text { spines. } & \text { Spine Journal } 17 & \text { (6) } 863-874 .\end{array}$ doi:10.1016/j.spinee.2017.01.013

[34] Wilcox RK (2006) The biomechanical effect of vertebroplasty on the adjacent vertebral body: a finite element study. Proc Inst Mech Eng H 220 (4):565-572. doi:10.1243/09544119H00305

[35] Teng MM, Wei CJ, Wei LC, Luo CB, Lirng JF, Chang FC et al. (2003) Kyphosis correction and height restoration effects of percutaneous vertebroplasty. AJNR Am J Neuroradiol 24 (9):1893-1900

[36] Chiu CK, Lisitha KA, Elias DM, Yong VW, Chan CYW, Kwan MK (2018) Do the 
dynamic stress mobility radiographs predict the postoperative vertebral height restoration, kyphosis correction, and cement volume injected after vertebroplasty for osteoporotic thoracolumbar vertebral fractures with intravertebral cleft? J Orthop Surg (Hong Kong) $26 \quad$ (3):2309499018806700. doi:10.1177/2309499018806700 


\section{Figure legends}

Figure 1. Evaluation of vertebral compression fractures on MR images. A: On sagittal T2W images, the vertebra is slightly collapsed and there is a fracture line inside (white arrow). B: On sagittal T2W SPAIR MR images, there is significant edema within the vertebral body (white arrow), suggesting a acute fracture.

Figure 2. Quantitative measurements of disc degeneration, vertebral body heights and kyphotic angles were acquired on the mid-sagittal T2W MR image. A: In this case of L3 fractures augmented with bone cement, L2/3 disc (*) and L3/4 disc (\#) were defined as the cranial and caudal adjacent discs, respectively, and L1/2 disc ( $($ ) was defined as the internal control disc. B: The anterior (a and a') and posterior ( $p$ and p') edges of cranial and caudal endplates, and middle points ( $\mathrm{m}$ and $\mathrm{m}$ ') were defined to obtain distance measurements of aa', pp' and mm', which were averaged as a disc height measurement. C: Disc bulging was measured as the area of the disc portion exceeding anterior or posterior adjacent vertebral edges. D: Mean disc signal was sampled in the anterior, middle and posterior regions of nucleus pulposus by defining three equivalent regions of interest (green squares). The mean signal of adjacent CSF (green circle) was also sampled and used as a reference to adjust disc signal measurement. Signal measurement, thus, is a percentage ratio. E: Vertebral body heights was defined as the mean of anterior (aa'), middle (mm') and posterior (pp') heights of the vertebra. F: Vertebral wedge angle was measured as the angle between superior and inferior endplates of the fractured vertebra. G: Segmental kyphotic angle was measured as the angle between superior and inferior endplates of two adjacent vertebrae. 
Table 1. Summary of subjects with or without kyphoplasty

One hundred and twelve fresh vertebral compression fractures were identified among

\begin{tabular}{lccc}
\hline & $\begin{array}{c}\text { Kyphoplasty } \\
(\mathrm{N}=66)\end{array}$ & $\begin{array}{c}\text { Conservative } \\
\text { treatments } \\
(\mathrm{N}=35)\end{array}$ & $\mathrm{P}$ \\
\hline Age (years) & $72.4 \pm 9.0$ & $70.2 \pm 7.6$ & 0.21 \\
Gender (male/female) $^{*}$ & $21 / 45$ & $10 / 25$ & 0.74 \\
Follow-up time (months) & $19.2 \pm 13.2$ & $25.6 \pm 18.1$ & 0.03 \\
Body mass index $\left(\mathrm{kg} / \mathrm{m}^{2}\right)$ & $22.3 \pm 4.0$ & $21.2 \pm 3.9$ & 0.28 \\
Vertebral fractures & & & 0.07 \\
T11 & $4(5.5 \%)$ & $4(10.0 \%)$ & \\
T12 & $15(20.8 \%)$ & $14(35.0 \%)$ & \\
L1 & $21(29.2 \%)$ & $9(22.5 \%)$ & \\
L2 & $16(22.2 \%)$ & $3(7.5 \%)$ & \\
L3 & $12(16.7 \%)$ & $3(7.5 \%)$ & \\
L4 & $3(4.2 \%)$ & $5(12.5 \%)$ & \\
L5 & $1(1.4 \%)$ & $2(5.0 \%)$ & \\
Total & 72 & 40 & \\
\hline
\end{tabular}

the 101 subjects included in this study.

${ }^{*} \chi^{2}$ tests were used. 
Table 2. Reliability for various measurements (ICC and 95\% CI, N=20)

\begin{tabular}{lll}
\hline Measurements & Intra-rater agreement & Inter-rater agreement \\
\hline Disc degeneration & & \\
$\quad$ Disc height & $0.89(0.84-0.92)$ & $0.78(0.69-0.85)$ \\
$\quad$ Disc bulging & $0.70(0.60-0.79)$ & $0.63(0.48-0.75)$ \\
$\quad$ Disc signal intensity & $0.95(0.93-0.97)$ & $0.91(0.88-0.94)$ \\
Vertebral height & $0.85(0.78-0.90)$ & $0.82(0.74-0.88)$ \\
Vertebral wedge angle & $0.94(0.88-0.97)$ & $0.80(0.66-0.89)$ \\
Segmental kyphotic angle & $0.99(0.98-1.00)$ & $0.96(0.93-0.98)$ \\
\hline
\end{tabular}

ICC: intra-class correlation coefficient; $95 \% \mathrm{CI}$ : 95\% confidence interval. 
Table 3. Measurements of the adjacent discs of the fractured vertebra with or without kyphoplasty treatment

\begin{tabular}{|c|c|c|c|c|c|c|c|c|c|c|}
\hline \multirow{2}{*}{$\begin{array}{l}\text { Disc } \\
\text { degeneration }\end{array}$} & \multirow{2}{*}{ kyphoplasty } & \multicolumn{3}{|c|}{ Cranial adjacent disc } & \multicolumn{3}{|c|}{ Caudal adjacent disc } & \multicolumn{3}{|c|}{ Internal control disc } \\
\hline & & Baseline & Follow-up & $\mathrm{P}$ & Baseline & Follow-up & $\mathrm{P}$ & Baseline & Follow-up & $\mathrm{P}$ \\
\hline $\begin{array}{l}\text { Disc height } \\
(\mathrm{mm})\end{array}$ & No & $6.89 \pm 2.37$ & $6.55 \pm 2.00$ & 0.10 & $7.76 \pm 2.59$ & $7.91 \pm 2.47$ & 0.37 & $6.94 \pm 1.92$ & $6.39 \pm 1.64$ & 0.03 \\
\hline $\begin{array}{l}\text { Disc signal } \\
\text { intensity }\left(\times 10^{-2}\right)\end{array}$ & $\begin{array}{l}\text { No } \\
\text { Yes }\end{array}$ & $\begin{array}{c}24.74 \pm 11.17 \\
23.33 \pm 8.84\end{array}$ & $\begin{array}{c}22.57 \pm 12.36 \\
20.35 \pm 8.85\end{array}$ & $\begin{array}{l}0.27 \\
0.01\end{array}$ & $\begin{array}{l}21.48 \pm 9.53 \\
19.06 \pm 8.50\end{array}$ & $\begin{array}{l}20.26 \pm 8.66 \\
16.97 \pm 8.58\end{array}$ & $\begin{array}{l}0.32 \\
0.02\end{array}$ & $\begin{array}{l}19.09 \pm 9.20 \\
17.77 \pm 8.23\end{array}$ & $\begin{array}{c}21.84 \pm 10.63 \\
17.53 \pm 8.78\end{array}$ & $\begin{array}{l}0.09 \\
0.81\end{array}$ \\
\hline $\begin{array}{l}\text { Anterior disc } \\
\text { bulging }\left(\mathrm{mm}^{2}\right)\end{array}$ & Yes & $\begin{array}{l}32.21 \pm 16.74 \\
22.37 \pm 11.92\end{array}$ & $\begin{array}{l}31.74 \pm 17.33 \\
21.82 \pm 11.32\end{array}$ & 0.62 & $34.74 \pm 17.55$ & $31.91 \pm 14.91$ & 0.25 & $27.06 \pm 10.25$ & $27.13 \pm 8.98$ & 0.97 \\
\hline
\end{tabular}

Data were mean $\pm \mathrm{SD}$. $\mathrm{N}=72$ vertebrae in kyphoplasty group and 40 in conservative treatments group.

The disc proximal to the fractured spinal motion segment was measured as an internal control disc. 
1 Table 4. Measurements of creep deformity and kyphotic angles at baseline and follow-up 2

\begin{tabular}{|c|c|c|c|c|c|c|c|}
\hline \multirow{2}{*}{\multicolumn{2}{|c|}{ Measurement }} & \multicolumn{3}{|c|}{$\begin{array}{l}\text { Conservative treatments } \\
\qquad(\mathrm{N}=40)\end{array}$} & \multicolumn{3}{|c|}{$\begin{array}{l}\text { Kyphoplasty } \\
\qquad(\mathrm{N}=72)\end{array}$} \\
\hline & & Baseline & Follow-up & $\mathrm{P}$ & Baseline & Follow-up & $\mathrm{P}$ \\
\hline \multirow{3}{*}{$\begin{array}{l}\text { Vertebral } \\
\text { height } \\
(\mathrm{mm})\end{array}$} & $\begin{array}{l}\text { Cranial adjacent } \\
\text { vertebra }\end{array}$ & $20.23 \pm 2.96$ & $20.40 \pm 2.82$ & 0.14 & $21.48 \pm 3.14$ & $21.17 \pm 3.37$ & 0.09 \\
\hline & Fractured vertebra & $17.54 \pm 3.44$ & $16.27 \pm 3.97$ & 0.002 & $19.97 \pm 3.59$ & $18.11 \pm 3.87$ & $<0.001$ \\
\hline & $\begin{array}{l}\text { Caudal adjacent } \\
\text { vertebra }\end{array}$ & $21.74 \pm 2.88$ & $21.17 \pm 3.24$ & 0.07 & $23.51 \pm 2.54$ & $22.86 \pm 2.77$ & 0.003 \\
\hline \multicolumn{2}{|c|}{$\begin{array}{l}\text { Adjusted height of the } \\
\text { fractured vertebra }(\%)\end{array}$} & $84.25 \pm 17.26$ & $78.56 \pm 17.97$ & 0.01 & $90.78 \pm 15.38$ & $83.57 \pm 17.29$ & $<0.001$ \\
\hline \multicolumn{2}{|c|}{$\begin{array}{l}\text { Wedge angle of the fractured } \\
\text { vertebra (degree) }\end{array}$} & $10.08 \pm 6.48$ & $12.81 \pm 7.80$ & 0.01 & $6.57 \pm 4.69$ & $10.08 \pm 6.11$ & $<0.001$ \\
\hline \multicolumn{2}{|c|}{$\begin{array}{l}\text { Segmental kyphotic angle } \\
\text { (degree) }\end{array}$} & $19.08 \pm 14.54$ & $20.39 \pm 14.41$ & 0.24 & $13.83 \pm 11.38$ & $16.52 \pm 12.34$ & $<0.001$ \\
\hline
\end{tabular}

3 Data were mean \pm SD.

4 


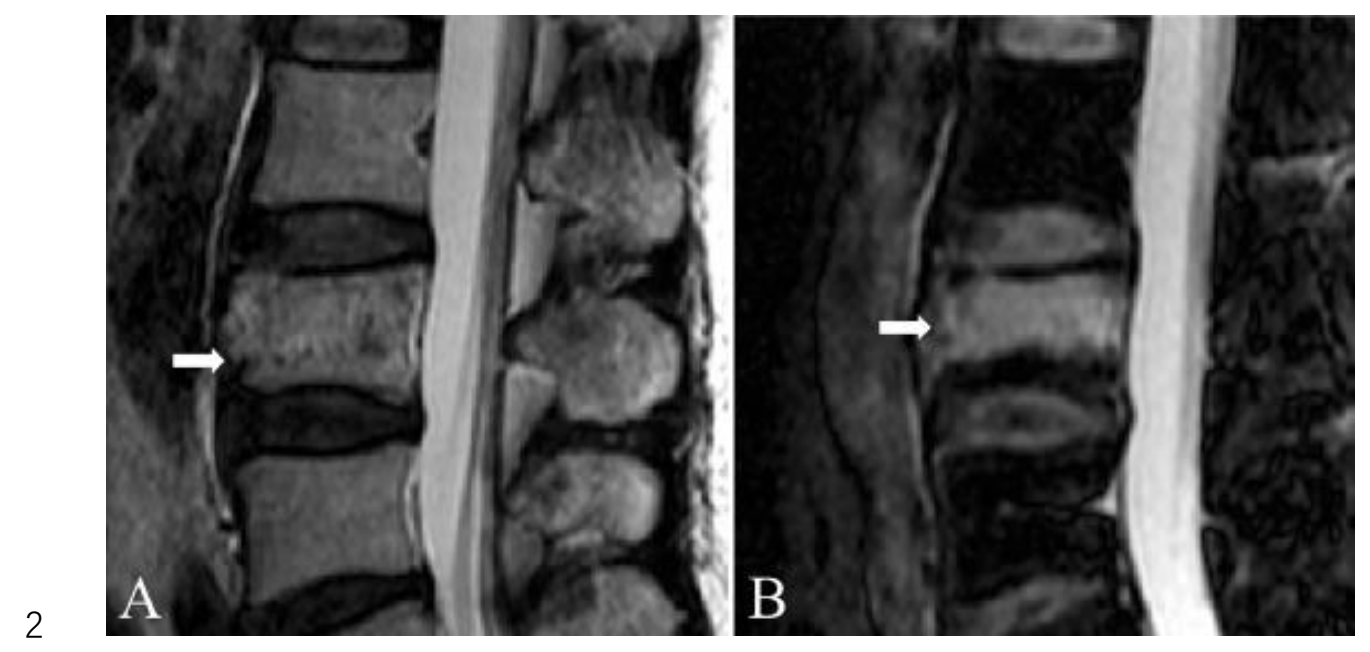

$3 \quad$ Figure 1

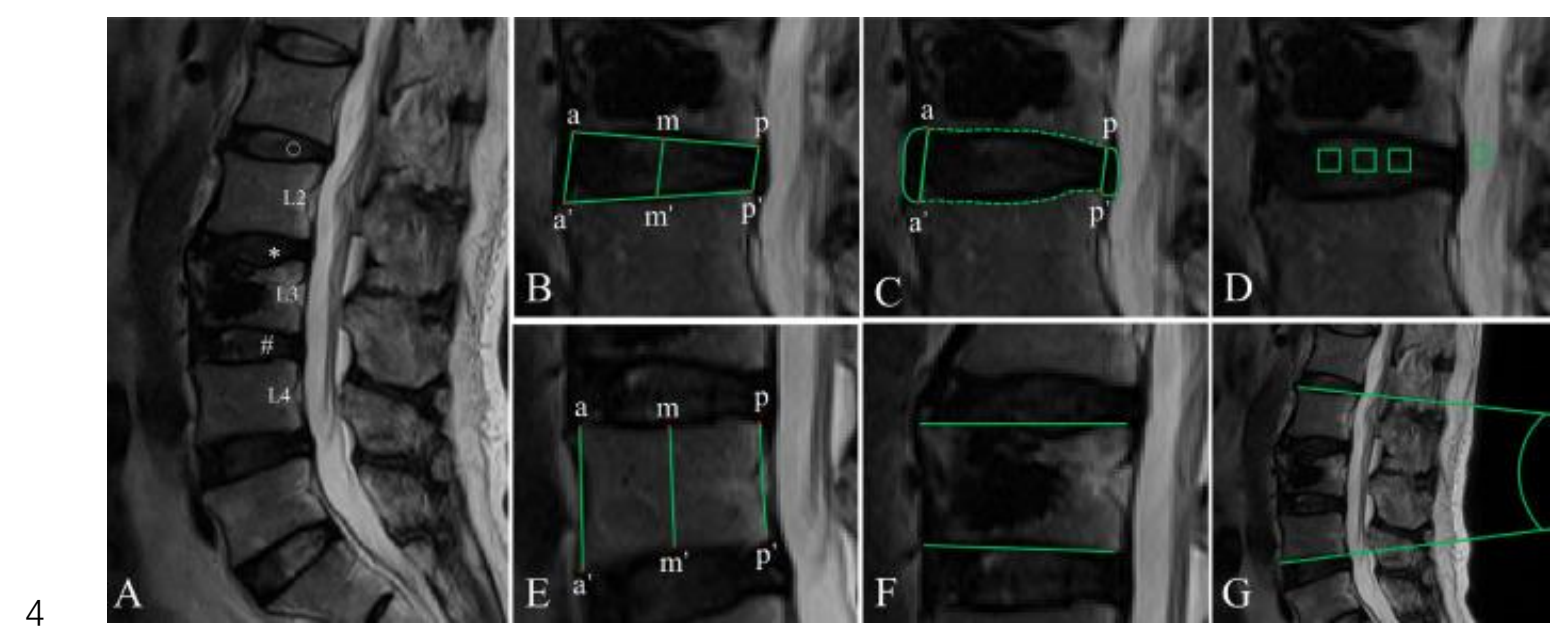

5 Figure 2 